бар урбанизачия орталықтарын құлыптастыруды мемлекеттік басқарудың негізгі бавыттарын қарастырды.

Мақалада қазіргі кезеңдегі урбанизация урдісінің негізгі тенденциялары қарастырылган, атап айтқанда урбанизация жеткілікті жовары деңзгейге жеткен экономикалық дамыван елдерде қала халқының үлесі баяу қарқынмен өсуде, ал дамушы елдерде урбанизачия үрдісі кеңейе береді және стихияль, бақыланбайтын сипатқฺ ие.

Түйінді сөздер: урбанизачия, агломерация, қ̧ала, аймақ, хальқ, обльıс ортальљ, аймақ̧тық саясат.

\title{
TERRITORIAL AND ECONOMIC ASPECTS OF URBANIZATION IN KAZAKHSTAN
}

\author{
Bekenova L.M., Seitkhamzina G.Zh., *Akhatova E.Kh. \\ Almaty Humanitarian and Economic University, Almaty, Kazakhstan \\ e-mail: eahatova@mail.ru
}

\begin{abstract}
Summary. The purpose of the work is to study the issues of territorial and economic development in the framework of regulated activation of urbanization in the Republic of $\mathrm{Ka}$ zakhstan.

The authors studied the main provisions of regional policy, considered the main directions of public administration in the formation of urbanization centers, which play a key role in the optimization of regional economic systems in cities with a population of one million.

Materials and research methods. A complex of the following research methods was used, when studying the territorial and economic features of urbanization in Kazakhstan: monographic, program-targeted, statistical analysis. The authors also used such theoretical research methods as comparisons and generalizations, scientific abstraction and synthesis. gional policy.

Key words: urbanization, agglomeration, city, region, population, regional center, re-
\end{abstract}

МРНТИ 27.03.17

УДК 519.1-519.8

https://doi.org/10.51579/1563-2415.2021-3.04

\section{УПРАВЛЕНИЯ ПРИ УСЛОВИЯХ РАСПРЕДЕЛЕНИЯ ОГРАНИЧЕННЫХ РЕСУРСОВ ПО МНОЖЕСТВУ НЕЗАВИСИМЫХ ПРОЕКТОВ}

\author{
В. Б. Кулик ${ }^{1}$, Д.И.Разакова $*^{2}$ А.Д. Тлеубекова ${ }^{3}$ \\ ${ }^{1}$ Университет «Туран», Алматы, Казахстан \\ 2,3 Алматинский гуманитарно-экономический университет, Алматы, Казахстан \\ e-mail: dinanext@mail.ru
}

\begin{abstract}
Аннотация. В статье представлено описание классификации задач распределения ресурсов по независимым проектам, предложены методы и алгоритмы решения оптимизачионной задачи с помощью сетевой модели распределения ресурсов в мультипроекте.
\end{abstract}


Главной проблемой экономики является выбор эффективного способа сочетания факторов производства с иелью решения проблем, возникающих из-за бесконечности потребностей и ограниченности ресурсов.

Экономическая эффективность характеризует эффективность использования факторов производства или ограниченных ресурсов. Исследует пути полного использования ограниченных ресурсов с целью максимального удовлетворения неограниченных потребностей общества.

Конечным результатом производства является эффективность общественного производства в отношении затрат факторов производства. Рост эффективности общественного производства проявляется как достижение больших конечных результатов при минимальном расходовании трудовых, материальнылх, природнылх $и$ финансовых ресурсов.

Ключевье слова: теория графов, двудольная сеть, распределение ресурсов, непрерывная зависимость.

Основные положения. В процессе написания статьи были достигнуты следующие основные результаты: исследование технологии внедрения автоматизированных систем учета и управления предприятием на основе использования современных информационных технологий и разработка конкретных рекомендаций по оптимизации проектов локализации ПП зарубежных производителей применительно к местным условиям. Для достижения поставленной цели в работе была определена задача исследования возможностей оптимизации ресурсной составляющей проектов внедрения.

Введение. В последние годы отмечается устойчивый интерес к компьютерным системам, способным обеспечить эффективное управление предприятием. Современная организация демонстрирует сегодня тесное переплетение информационных технологий и бизнес-процессов основной деятельности. В связи с этим, вопросы управления организацией нельзя рассматривать без изучения проблем их автоматизации.

Материалы и методы. Объектом исследования является информационная система (ИС) управления и учета на различных предприятиях республики и процесс внедрения автоматизированных ИС. Предметом исследования является мультипроект по созданию линейки тиражных локализованных программных решений для автоматизации казахстанских предприятий.

Результаты. В ходе исследования проблемы, была получена и опубликована [1, 2], приведенная ниже, классификация задач, которые рассматриваются в данной работе.

Во-первых, задачи можно классифицировать по видам ресурсов, используемых для выполнения работ, входящих в мультипроект. В качестве первого основания классификации примем вид ресурсов, выполняющих первые, вторые и третьи работы каждого проекта.

По данному признаку можно выделить пять классов задач.

Класс А. Первые, вторые и третьи работы проектов выполняются различными видами ресурсов.

Класс Б. Первые и вторые работы проектов выполняются одним видом ресурсов, а третьи - другим.

Класс В. Первые и третьи работы проектов выполняются одним видом ресурсов, а вторые - другим

Класс Г. Вторые и третьи работы проектов выполняются одним видом ресурсов, а первые - другим.

Класс Д. Все работы проектов выполняются одним видом ресурсов. 
В качестве второй характеристики для классификации рассматриваемых задач можно принять вид зависимости скорости выполнения работ от количества ресурсов. Итак, во втором основании классификации выделим два класса задач. В первом классе, зависимость скорости работ от количества ресурсов является непрерывной, а во втором - дискретной. Первый класс задач, в котором количество используемых ресурсов принимает вещественные значения из интервала $\left(0, N_{j}\right)$ будем обозначать буквой $\mathrm{H}$, а второй, в котором $U_{i j}$ принимает целочисленные значения из интервала $\left(0, N_{j}\right)$ будем обозначать буквой Д.

Тогда классы задач распределения ресурсов будем обозначать двумя буквами, первая из которых выделяет задачу по первому основанию классификации, а вторая по второму.

Так, например, обозначение БД означает класс задач, в которых первые и вторые работы проектов выполняются одним видом ресурсов, третьи - другим, а зависимости скорости работ от количества ресурсов являются дискретными.

Обсуждение. Следуя данной концепции, всего получаем 10 классов задач.

Рассмотрим возможные методы решения задач и результаты экспериментов для класса АН.

Задачи этого класса в общем случае относятся к так называемым NP-трудным задачам, не имеющим эффективных точных методов решения [3]. Примем, что зависимость $f_{i j}\left(u_{i j}\right)$ имеет вид:

$$
f_{i j}\left(u_{i j}\right)= \begin{cases}u_{i j}, & u_{i j} \leq a_{i j} \\ a_{i j}, & u_{i j} \geq a_{i j}\end{cases}
$$

Обозначим $N_{j}, j=1,2,3$ количество ресурсов $j$-го вида. Покажем, что существует оптимальное решение, в котором все работы выполняются максимальным количеством ресурсов (возможно с перерывами в работе) за время

$$
\tau_{i j}=\frac{W_{i j}}{a_{i j}}
$$

Действительно, пусть не некоторой работе $(i, j) \boldsymbol{\varkappa}_{i j}<\boldsymbol{V}_{j} \quad$ в течение интервала $\tau$. Тогда на какой-либо другой работе $(k, j)$ этого же типа $u_{k j}<N_{j}$ в течение того же интервала (или на нескольких работах). За время $\tau$ будет выполнено $W_{i j}=u_{i j} \tau$ объема работы $(i, j)$ и $W_{k j}=u_{k j} \tau$ объема работы $(k, j)$. Определим другой календарный план. Сначала ресурсы $N_{j}$ направляются на работу $(i, j)$. Объем работ $W_{i j}$ будет выполнен за время

$$
\tau_{i}=\frac{u_{i j} \tau}{N_{j}}<\tau
$$

Затем ресурсы направляются на работу $(k, j)$. Объем работы $W_{k j}$ будет выполнен за время 


$$
\tau_{j}=\frac{W_{k j}}{N_{j}}=\frac{u_{k j} \tau}{N_{j}}<\tau
$$

и работа будет завершена в момент $\tau_{1}+\tau_{2}=\tau$.

Итак, в новом плане первая работа завершается ранее, а вторая - в то же время. Повторяя эту операцию каждый раз, когда $u_{i j}<N_{j}$, приходим к плану, в котором для всех работ $u_{i j}=N_{j}$, если работа выполняется.

В этом случае, получаем классическую «Задачу о станках», известную своей сложностью [3].

Рассмотрим несколько подклассов.

1. Ограничены ресурсы первого вида, то есть

$$
\sum_{i=1}^{n} a_{i}>>N_{1}
$$

Ресурсов второго и третьего вида достаточно и соответствующие работы выполняются за минимальные времена $\tau_{i 1}$.

2. Ограничены ресурсы второго вида, то есть

$$
\sum_{i=1}^{n} a_{i 2}>N_{2}
$$

Работы первого и третьего типа выполняются за минимальные времена $\tau_{i 2}$.

3. Ограничены ресурсы третьего вида, то есть

$$
\sum_{i=1}^{n} a_{i 3}>N_{3}
$$

Работы первого и второго типа выполняются за минимальные времена $\tau_{i 3}$.

4. Ограничены ресурсы первого и второго вида, то есть имеют место условия (2.3) и (2.4). Работы третьего типа выполняются за минимальное время $\tau_{i 3}$.

5. Ограничены ресурсы первого и третьего вида, то есть имеют место условия (2.3) и (2.5). Работы второго типа выполняются за минимальное время $\tau_{i 2}$.

6. Ограничены ресурсы второго и третьего вида, то есть имеют место условия (2.4) и (2.5). Работы первого типа выполняются за минимальное время $\tau_{i 1}$.

7. Ограничены ресурсы всех видов, то есть имеют место условия (2.3), (2.4) и (2.5).

Эксперимент 2.1. Результаты исследования планируется применять на проектах внедрения ИСУП, когда необходимо автоматизировать несколько функциональных областей деятельности на предприятии. В данном исследовании экспериментальная часть проводилась на примере проектов разработки ПП. При создании первой линейки седьмой версии планировалось подготовить четыре ПП по учету и управлению предприятием, то есть реализовать четыре проекта: 1 - предприятие, 2 - персонал, 3 - госучре- 
ждение, 4 - торговля. В таблице приведены данные об объемах проектирования, разработки, тестирования и продолжительности их выполнения.

Имеем $q_{1}=10, q_{2}=8, q_{3}=7, q_{4}=5$

Пусть $N_{1}=6$

Из условия (1.8) получаем начальную величину времени завершения мультипроекта

$$
T 1=\frac{60}{6}+5=15
$$

\section{Таблица 1}

Тестовые данные мультипроекта

\begin{tabular}{|c|c|c|c|c|c|}
\hline$i$ & 1 & 2 & 3 & 4 & $V_{i}$ \\
\hline$W_{i 1}$ & 12 & 10 & 18 & 20 & 60 \\
\hline$W_{i 2}$ & 18 & 9 & 20 & 12 & 59 \\
\hline$W_{i 3}$ & 24 & 15 & 8 & 18 & 65 \\
\hline$a_{i 1}$ & 4 & 2 & 3 & 5 & \\
\hline$a_{i 2}$ & 3 & 3 & 4 & 6 & \\
\hline$a_{i 3}$ & 6 & 3 & 4 & 6 & \\
\hline$\tau_{i 1}$ & 3 & 5 & 6 & 4 & \\
\hline$\tau_{i 2}$ & 6 & 3 & 5 & 2 & \\
\hline$\tau_{i 3}$ & 4 & 5 & 2 & 3 & \\
\hline
\end{tabular}

На рисунке 2 приведен двудольный граф, где числа в скобках равны пропускным способностям, без скобок - реальному потоку. Задачу нахождения максимального потока в сети, вычисляем по алгоритму Форда - Фалкерсона. Величина равна 58. Получаем условие $58<V_{1}=60$. Следовательно, $T_{1}$ - необходимо увеличить. Заметим, что увеличение $T$ увеличивает пропускные способности только дуг $c_{i 1}(i=\overline{1, n})_{\text {и }} c_{1 z}$.

Минимальное увеличение $T$ составляет

$$
\delta=\frac{60-58}{N_{1}}=\frac{2}{6}=\frac{1}{3}
$$

Это позволяет увеличить поток по дугам $(0,1),(1,1)$ и $(1, \mathrm{z})$ на 2 единицы. Полученный поток насыщает входные дуги. Поэтому получается оптимальное решение с продолжительностью мультипроекта равной

$$
T_{\min }=\frac{62}{6}+5=15 \frac{1}{3} \text {. }
$$




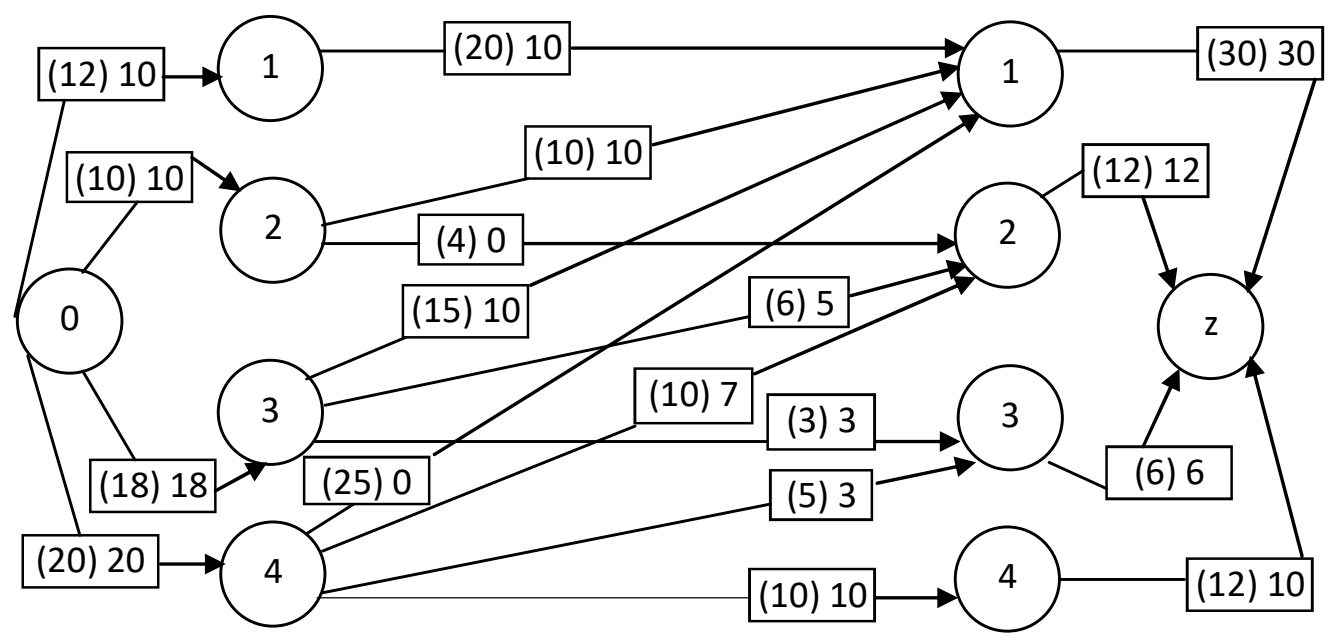

Рисунок 2 - Двудольная сеть эксперимента 2.1 для случая $T_{1}=15$

\section{Подкласс АН2}

В этом подклассе ограничены ресурсы второго вида. Соответственно, продолжительности работ первого и третьего типа равны минимальным $\tau_{i 1}$ и $\tau_{i 3}$. Заметим, что продолжительности $\tau_{i 1}$ определяют ранние моменты начала работ второго типа, которые равны $t_{i}^{\rho}=\tau_{i 1}$, а продолжительности $\tau_{i 3}$ при заданном $T$ определяют поздние сроки окончания работ второго типа, которые равны $t_{i}^{n}=T-\tau_{i 3}$. Аналогично подклассу $A H 1$ построим двудольную сеть, вершины первого слоя которой соответствуют проектам, а вершины второго слоя - интервалам времени, соответствующим моментам $t_{i}^{\rho}$ и $t_{i}^{n}$, упорядоченным по возрастанию. Способ построения вершин второго слоя продемонстрируем с помощью эксперимента.

Эксперимент 2.2. Возьмем данные эсперимента 2.1. из таблицы 2. Пусть $N_{2}=6$. Сначала получим оценку снизу для продолжительности мультипроекта. Для этого заметим, что ранний срок начала работ второго типа равен $\tau_{i 1}=3$. После завершения всех работ второго типа потребуется не менее $\tau_{i 3}=2$ единиц времени для завершения мультипроекта. Наконец, выполнение всех работ второго типа потребует не менее

$$
T_{2}=\frac{V_{2}}{N_{2}}=\frac{59}{6} \approx 10
$$

С другой стороны, выполнение 2-й работы $i$-го проекта с максимальной интенсивностью $a_{i 2}$ потребует $\tau_{i 2}$ единиц времени, что дает минимальную продолжительность $i$-го проекта

$$
T_{2}=\tau_{i 1}+\tau_{i 2}+\tau_{i 3}
$$


Таким образом, получаем оценку снизу продолжительности мультипроекта

$$
T \geq \max \left[\min _{i} \tau_{i 1}+\min _{i} \tau_{i 3}+\frac{V_{2}}{N_{2}} ; \quad \max _{i}\left(\tau_{i 1}+\tau_{i 2}+\tau_{i 3}\right)\right]
$$

Для рассматриваемого случая, с точностью до целых чисел, имеем

$$
T \geq \max [3+2+59 / 6 ; \quad \max (13 ; 13 ; 13 ; 9)] \approx 15
$$

Возьмем $T_{1}=15$. В таблице 2 приведены ранние времена начала и поздние времена окончания работ 2-ого типа при $T_{1}=15$ по данным взятым из таблицы 2.

Таблий 2

Ранние времена начала и поздние окончания работ 2-го типа

\begin{tabular}{|c|c|c|c|c|}
\hline$i$ & 1 & 2 & 3 & 4 \\
\hline$t_{i}^{R N}$ & 3 & 5 & 6 & 4 \\
\hline$t_{i}^{0}$ & $15-4=11$ & $15-5=10$ & $15-2=13$ & $15-3=12$ \\
\hline
\end{tabular}

Упорядочим эти моменты по возрастанию

$$
t_{1}^{H}<t_{4}^{H}<t_{2}^{H}<t_{3}^{H}<t_{1}^{o}<t_{4}^{o}<t_{3}^{o}
$$

и определим длительности $\Delta_{S}$ интервалов между этими моментами, отраженные в таблице 3.

\section{Таблича 3}

Длительности интервалов для работ 2-ого типа

\begin{tabular}{|l|l|l|l|l|l|l|l|}
\hline$S$ & 1 & 2 & 3 & 4 & 5 & 6 & 7 \\
\hline$\Delta S$ & 1 & 1 & 1 & 4 & 1 & 1 & 1 \\
\hline
\end{tabular}

Поясним таблицу 2.3. Первый интервал - это $\left(t_{1}^{H} ; t_{4}^{H}\right)$ длительности 1 , второй $\left(t_{4}^{H} ; t_{2}^{H}\right)$ длительности 1 , третий - $\left(t_{2}^{H} ; t_{3}^{H}\right)$ длительности 1 , четвертый $-\left(t_{2}^{o} ; t_{3}^{H}\right)$ длительности 4 и т. д.

Теперь можно построить двудольную сеть, представленную на рисунке 3. Первый слой вершин, как и ранее соответствует проектам, а второй слой - интервалам. Дуга $(i, s)$ соединяет вершину $i$ с вершиной $s$, если работа может выполниться в интервале $s$. 
Эксперимент 2.3. Возьмем данные эксперимента 2.2. из таблицы 1. Примем $N_{3}=8, \quad r=2, \quad V_{3}(2)=12$. Оценка равна

$$
T \bullet \geq \Delta_{1}+\frac{65-12}{8}+6=14 \frac{5}{8}
$$

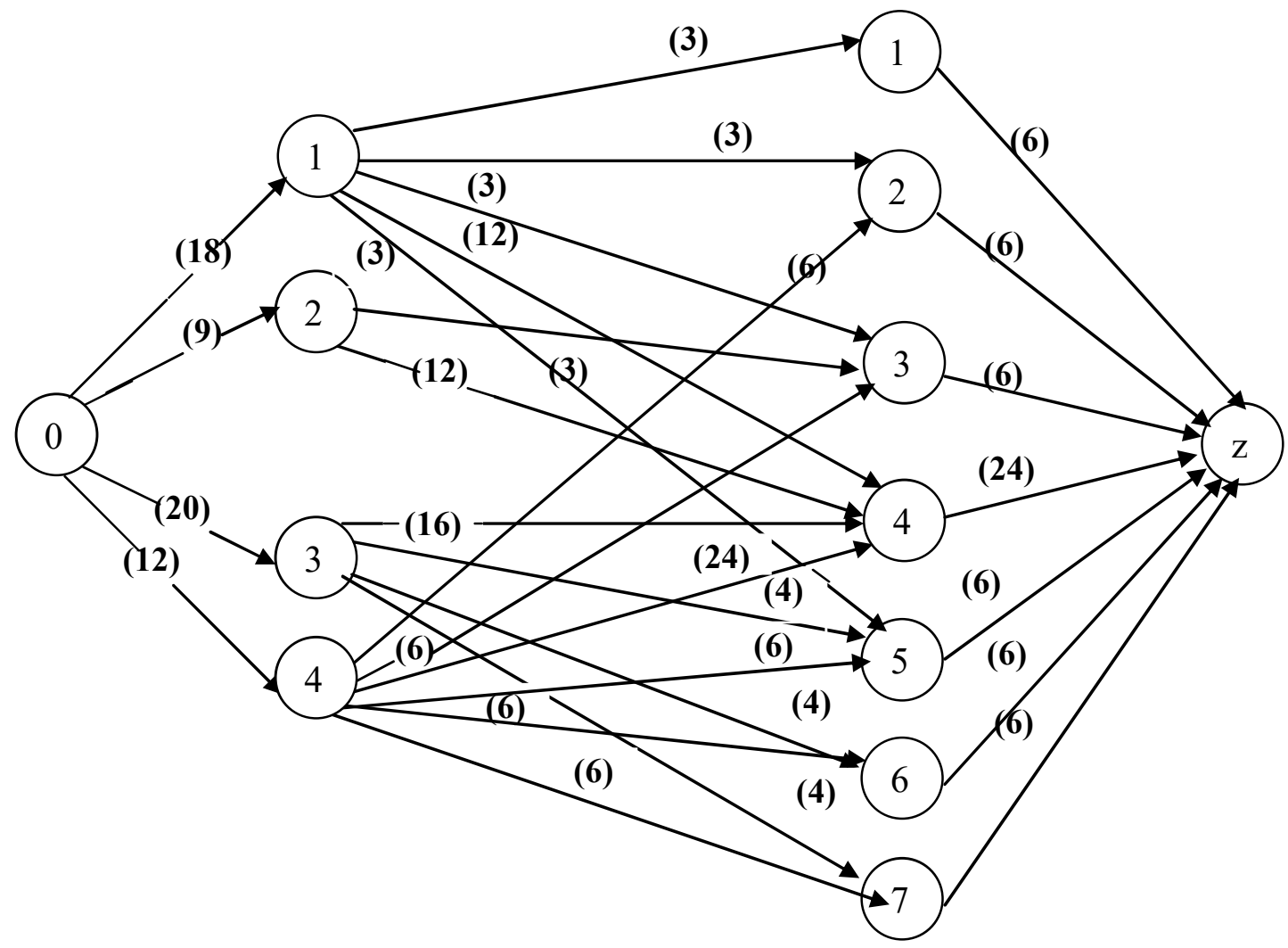

Рисунок 3 - Двудольная сеть для задач класса АН2

Заметим, что оценка, полученная по аналогии с предыдущими случаями равна

$$
c_{1}+\frac{V_{3}}{N_{3}}=6+\frac{65}{8}=14 \frac{1}{8}<14 \frac{5}{8} \text {. }
$$

Двудольный граф для случая $T=15$ приведен на рисунке 4 .

В данном случае максимальный поток насыщает входные дуги и поэтому полученное решение является оптимальным (с точностью до целочисленности $T$ ).

Для этого подкласса рассмотрим также нелинейные вогнутые зависимости $f_{i 3}\left(u_{i 3}\right)$. А именно, примем, что

$$
f_{i 3}\left(u_{i 3}\right)=u_{i 3}^{\alpha} ; \quad i=\overline{1, n}
$$




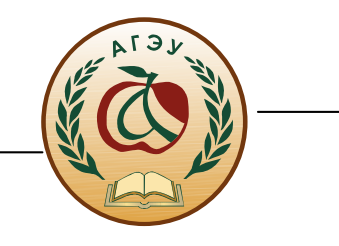

где $\alpha<1$. Для случая $p_{i}=0, i=\overline{1, n}$ (то есть отсутствуют работы первого и второго типов) В.Н. Бурковым [57] было доказано, что минимальная продолжительность мультипроекта равна

$$
\begin{gathered}
T_{\text {min }}=\frac{W_{\ni}}{N_{3}^{\alpha}}, \text { где } \\
W_{\ni}=\left[\sum W_{i 3}^{1 / \alpha}\right]^{\alpha}
\end{gathered}
$$

- эквивалентный объем мультипроекта. Дадим обобщение этого результата на подкласс AH3.

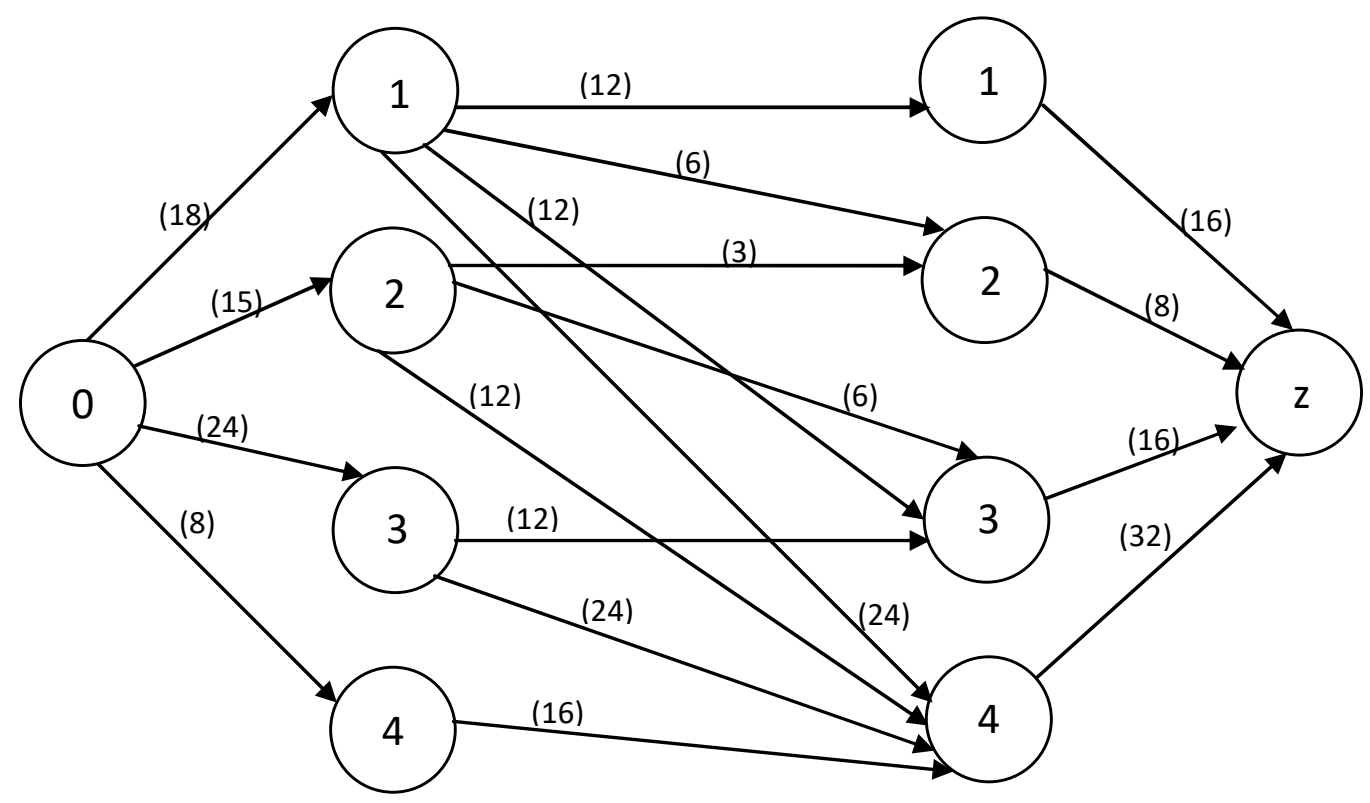

Рисунок 4 - Двудольный граф для задач класса АНЗ

Заключение. Результаты исследования сведены в таблицу 4, в которой описано для каких классов и подклассов известны точные алгоритмы решения [5], для каких известны эвристические алгоритмы [6] и для каких подклассов задач локализации алгоритмы решения предложены авторами [7] - точные или приблизительные.

I. Предложена 10-ти классовая систематизация задач ресурсного планирования. Мультипроект локализации ПО описан в виде сетевого графика комплекса работ и зависимостей скорости выполнения работы от количества ресурсов, ее выполняющих.

II. В каждом классе задач выделены подклассы в зависимости от ограничений на ресурсы различных видов. Предложены алгоритмы решения задач распределения ресурсов по мультипроекту, минимизирующему его продолжительность с помощью методов сетевого программирования [8-22].

Ш. Приведена таблица результатов исследования с указанием для каких классов и подклассов известны точные алгоритмы решения, для каких известны эвристические 
алгоритмы и для каких подклассов задач алгоритмы решения предложены авторами точные или приблизительные.

Таблий 4

Результаты исследования алгоритмов решения задач

\begin{tabular}{|c|c|c|c|c|}
\hline Классы и подклассы & $\begin{array}{l}\text { Эвристич. } \\
\text { алгоритмы }\end{array}$ & $\begin{array}{c}\text { Точные алго- } \\
\text { ритмы }\end{array}$ & $\begin{array}{c}\text { Эвристич. } \\
\text { алгоритмы } \\
\text { авторов }\end{array}$ & $\begin{array}{c}\text { Точные } \\
\text { алгоритмы } \\
\text { авторов }\end{array}$ \\
\hline $\begin{array}{l}\text { АН1, АН2, АН3 } \\
\text { АН3 (нелинейные } \\
\text { Зависимости) АН4:- } \\
\text { АН7 }\end{array}$ & + & & & $\begin{array}{c}+++ \\
+\end{array}$ \\
\hline $\begin{array}{l}\text { АД1, АД2, АД3 } \\
\text { АД4-АД7 }\end{array}$ & + & & & +++ \\
\hline $\begin{array}{l}\text { БН1 } \\
\text { БН1 (частн. случ.) } \\
\text { БН2 }\end{array}$ & + & & + & + \\
\hline $\begin{array}{l}\text { БД1 } \\
\text { БД2 } \\
\text { БД2(частн. случ.) }\end{array}$ & + & $\begin{array}{l}\text { + задача Джон- } \\
\text { сона }\end{array}$ & + & \\
\hline $\begin{array}{l}\text { BН1 } \\
\text { ВН1 (частн. случ.) } \\
\text { ВН2 }\end{array}$ & $\begin{array}{l}+ \\
+\end{array}$ & $\begin{array}{l}\text { +задача редак- } \\
\text { тора (Бурков) }\end{array}$ & & \\
\hline $\begin{array}{l}\text { ВД1 } \\
\text { ВД1(частн. случ.) } \\
\text { ВД2 }\end{array}$ & $\begin{array}{l}+ \\
+ \\
+\end{array}$ & $\begin{array}{l}\text { +задача редак- } \\
\text { тора (Бурков) }\end{array}$ & & \\
\hline $\begin{array}{l}\text { ГН1 } \\
\text { ГН2 } \\
\text { Гд1, } \\
\text { ГД2 } \\
\text { ГД3 (частн. случ.) } \\
\text { ДН } \\
\text { ДН (частн. случ.) } \\
\text { ДД }\end{array}$ & $\begin{array}{l}+ \\
+ \\
+ \\
+\end{array}$ & $\begin{array}{l}\text { + Задача Джон- } \\
\text { сона } \\
\text { + Бурков }\end{array}$ & & $\begin{array}{l}+ \\
+ \\
+ \\
+\end{array}$ \\
\hline
\end{tabular}

\section{Список литературы:}

1 Кулик В.Б., Возможности реализации технологии внедрения автоматизированных систем управления предприятием, Статистика, учет и аудит.- Алматы, 2009.№3(34), C.153-161.

2 Кулик В.Б., Русаковский А.М. Распределение ресурсов по множеству независимых проектов// Труды международной научно-практической мультиконференции «Управление большими системами-2009», Москва, Россия, 2009 г., «Институт проблем управления РАН», том 2, с.42-44

3 Сигал И.Х., Иванова А.П. Введение в прикладное дискретное программирование. М.: ФИЗМАТЛИТ, 2007. - 304 с. 
4 Математические основы управления проектами. Учебное пособие под ред. В.Н. Буркова: /Учебное пособие/ - . - М.: Высшая школа. 2005. 240 с.

5 Бурков В.Н., Буркова И.В., и др. Задачи управления в социальных и экономических системах, М.: СИНТЕГ, 2005. 256 с.

6 Кулжабаев Н.М., Исследование операций: /Учебное пособие/ - Алматы, Республиканский издательский кабинет Казахской академии образования им. И.Алтынсарина, 1999-286 с.

7 Кулжабай Н.М., Кулик В.Б. Об особенностях внедрения автоматизированных информационных систем учета и управления предприятием// журнал Вестник Казахской академии транспорта и коммуникаций им. М.Тынышпаева, 2009г., №6, с.7/6

8 Кулик В.Б. Исследование этапа адаптации в технологии внедрения автоматизированных информационных систем// Труды международной научно-практической конференции «Устойчивое развитие агропромышленного комплекса и сельских территорий», Курган, Россия, 2008г., ФГОУ ВПО «Курганская государственная сельскохозяйственная академия имени Т.С. Мальцева», том 1, с.289-296

9 Кулжабай Н.М., Кулик В.Б. Исследование методов внедрения автоматизированных систем учета и управления на предприятиях// журнал Вестник КазНТУ им. К.И.Сатпаева, Алматы, 2008 г., №2(65), с.98-102.

\section{Spisok literatury:}

1. Kulik V.B., Vozmozhnosti realizatsii tekhnologii vnedreniia avtomatizirovannykh sistem upravleniia predpriiatiem, Statistika, uchet i audit.- Almaty, 2009.-№3(34), S.153-161.

2. Kulik V.B., Rusakovskii A.M. Raspredelenie resursov po mnozhestvu nezavisimykh proektov// Trudy mezhdunarodnoi nauchno-prakticheskoi multikonferentsii «Upravlenie bolshimi sistemami-2009», Moskva, Rossiia, 2009 g., «Institut problem upravleniia RAN», tom 2, c.42-44

3. Sigal I.Kh., Ivanova A.P. Vvedenie v prikladnoe diskretnoe programmirovanie. M.: FIZMATLIT, 2007. - 304 s.

4. Matematicheskie osnovy upravleniia proektami. Uchebnoe posobie pod red. V.N. Burkova: /Uchebnoe posobie/ - . - M.: Vysshaia shkola. 2005. $240 \mathrm{~s}$.

5. Burkov V.N., Burkova I.V., i dr. Zadachi upravleniia v sotsialnykh i ekonomicheskikh sistemakh, M.: SINTEG, 2005. $256 \mathrm{~s}$.

6. Kulzhabaev N.M., Issledovanie operatsii: /Uchebnoe posobie/ - Almaty, Respublikanskii izdatelskii kabinet Kazakhskoi akademii obrazovaniia im. I.Altynsarina, 1999-286 s.

7. Kulzhabai N.M., Kulik V.B. Ob osobennostiakh vnedreniia avtomatizirovannykh informatsionnykh sistem ucheta i upravleniia predpriiatiem// zhurnal Vestnik Kazakhskoi akademii transporta i kommunikatsii im. M.Tynyshpaeva, 2009g., №6, s.7/6

8. Kulik V.B. Issledovanie etapa adaptatsii $\mathrm{V}$ tekhnologii vnedreniia avtomatizirovannykh informatsionnykh sistem// Trudy mezhdunarodnoi nauchnoprakticheskoi konferentsii «Ustoichivoe razvitie agropromyshlennogo kompleksa i selskikh territorii», Kurgan, Rossiia, 2008g., FGOU VPO «Kurganskaia gosudarstvennaia selskokhoziaistvennaia akademiia imeni T.S. Maltseva», tom 1, c.289-296

9. Kulzhabai N.M., Kulik V.B. Issledovanie metodov vnedreniia avtomatizirovannykh sistem ucheta i upravleniia na predpriiatiiakh// zhurnal Vestnik KazNTU im. K.I.Satpaeva, Almaty, 2008 g., №2(65), s.98-102. 


\title{
ТӘУЕЛСІЗ ЖОБАЛАР ЖИЫНТЫҒЫ БОЙЫНША ШЕКТЕУЛІ РЕСУРСТАРДЫ ОРНАЛАСТЫРУ ЖАҒДАЙЫНДАҒЫ БАСҚАРУ
}

\author{
В. Б. Кулик ${ }^{1}$, Д.И.Разакова ${ }^{* 2}$ А.Д.Тлеубекова ${ }^{3}$ \\ ${ }^{1}$ «Тұран» университеті, Алматы, Қазақстан \\ ${ }_{2,3}$ Алматы гуманитарль--экономикалық университеті, Алматы, Қазақстан \\ e-mail: dinanext@mail.ru
}

Түйін. Мақалада тәуелсіз жобалар бойынша ресурстарды бөлу есептерін жіктеудің сипаттамасы берілген, мультипроектте ресурстарды бөлудің желілік моделін қолдана отырып, оңтайландыру мәселесін шешудің әдістері мен алгоритмдері ұсынылган.

Экономиканың негізгі проблемасы-қажеттіліктердің шексіздігі мен ресурстардың шектеулі болуына байланысты туындайтын мәселелерді шешу үшін өндіріс факторларын біріктірудің тиімді әдісін тацдау.

Экономикалық тиімділік өндіріс факторларын немесе шектеулі ресурстарды пайдалану тиімділігін сипаттайды. Қовамның шексіз қажеттіліктерін барынша қанаваттандыру мақсатында шектеулі ресурстарды тольқ пайдалану жолдарын зерттейді.

Өндірістің түпкілікті нәтижесі өндіріс факторларының шывындарына қатысты әлеуметтік өндірістің тиімділігі больп табылады. Әлеуметтік өндіріс тиімділігінің өсуі еңбек, материалдық, табиги және қаржылық ресурстарды аз жүмсау арқылы үлкен нәтижеге қол жеткізу ретінде көрінеді.

Түйінді сөздер: графтар теориясы, екі жақты желі, ресурстарды бөлу, үздіксіз тәуелділік.

\section{CONTROL UNDER DISTRIBUTION CONDITIONS LIMITED RESOURCES ON MANY INDEPENDENT PROJECTS}

\author{
V.B. Kulik1 ${ }^{1}$, D.I. Razakova ${ }^{* 2}$ A.D.Tleubekova ${ }^{3}$ \\ ${ }^{1}$ Turan University, Almaty, Kazakhstan \\ ${ }^{2,3}$ Almaty University of Humanities and Economics, Almaty, Kazakhstan \\ e-mail: dina_next@mail.ru
}

Summary. The article describes the classification of resource allocation tasks for independent projects, suggests methods and algorithms for solving the optimization problem using a network model of resource allocation in a multiproject.

The main problem of the economy is the choice of an effective way to combine factors of production in order to solve problems arising from the infinity of needs and limited resources.

Economic efficiency characterizes the efficiency of the use of production factors or limited resources. Explores ways to fully utilize limited resources in order to maximize the satisfaction of unlimited needs of society.

The final result of production is the efficiency of social production in relation to the costs of factors of production. The increase in the efficiency of social production is manifested as the achievement of large final results with minimal expenditure of labor, material, natural and financial resources.

Key words: graph theory, bipartite network, resource allocation, continuous dependence 